\title{
Elevated vitreous body glial fibrillary acidic protein in retinal diseases
}

\author{
Anselm Gerhard Maria Jünemann ${ }^{1} \cdot$ Robert Rejdak $^{2,3}$ • Cord Huchzermeyer ${ }^{1}$. \\ Ryszard Maciejewski $^{5}$ - Pawel Grieb ${ }^{3}$ - Friedrich E. Kruse ${ }^{1}$ - Eberhart Zrenner ${ }^{5}$. \\ Konrad Rejdak $^{3,4}$ • Axel Petzold ${ }^{6,7,8}$ (iD)
}

Received: 22 December 2014 / Revised: 16 July 2015 / Accepted: 28 July 2015 / Published online: 18 August 2015

(C) The Author(s) 2015. This article is published with open access at Springerlink.com

\begin{abstract}
Purpose Increased expression of glial fibrillary acidic protein (GFAP) is a characteristic of gliotic activation (Müller cells and astrocytes) in the retina. This study assessed vitreous body GFAP levels in various forms of retinal pathology.

Methods This prospective study included 82 patients who underwent vitrectomy (46 retinal detachments (RDs), 13 macular hole (MHs), 15 epiretinal glioses (EGs), 8 organ donors). An established enzyme-linked immunosorbent assay (ELISA, SMI26) was used for quantification of GFAP.

Results The highest concentration of vitreous body GFAP in organ donors was $20 \mathrm{pg} / \mathrm{mL}$ and it was used as the cutoff. A significant proportion of patients suffering from $\mathrm{RD}(65 \%)$ to
\end{abstract}

Axel Petzold

a.petzold@ucl.ac.uk

1 Department of Ophthalmology, University of Erlangen-Nurnberg, Erlangen, Germany

2 Department of General Ophthalmology, Medical University of Lublin, Lublin, Poland

3 Medical Research Centre, Polish Academy of Science, Warsaw, Poland

4 Department of Neurology, Medical University of Lublin, Lublin, Poland

5 Department of Anatomy, Medical University of Lublin, Lublin, Poland

6 Expertise Center Neuro-ophthalmology, Free University Medical Center, Amsterdam, The Netherlands

7 Department of Neuro-Ophthalmology, Moorfields Eye Hospital, City Road, London, UK

8 UCL Institute of Neurology, Queen Square, London WC1N 3BG, UK
EG (53\%) had vitreous body GFAP levels above this cutoff when compared to organ donors $(0 \%, p<0.0001, p=0.0194$, respectively, Fisher's exact test $)$ and $\mathrm{MH}(8 \%, p<0.0001, p=$ 0.0157 , respectively). In RD and EG, vitreous body GFAP levels were correlated with axial length $(R=0.69, R=0.52$, $p<0.05$ for both).

Conclusions The data suggest that human vitreous body GFAP is a protein biomarker for glial activation in response to retinal pathologies. Vitreous body GFAP levels may be of interest as a surrogate outcome for experimental treatment strategies in translational studies.

Keywords Vitreous - Glial fibrillary acidic protein (GFAP) · Biomarker $\cdot$ Retinal detachment $\cdot$ Epiretinal gliosis $\cdot$ Müller cells

\section{Introduction}

Glial fibrillary acid protein (GFAP) is a protein biomarker for astrocytes and activated Müller cells [1]. Müller cells are the principle glial cells in the neural retina, being involved in the homoeostasis and metabolism of retinal neurons $[2,3]$, and they penetrate the entire human retina in radial columns. Astrocytes are only found within the retinal nerve fibre layer (RNFL) and, notably, the optic nerve head (ONH). This protein biomarker is a non-soluble, 432-amino acid cytoskeletal protein belonging to the class-III intermediate filament proteins $[1,4]$. Discovered in 1969, it is encoded on chromosome 17q21.1-q25 [1,5]. Under normal conditions, GFAP is not expressed in Müller cells.

Activation of Müller cells including increased expression of GFAP is a key response feature of the human retina to injury and a sign of age-related subclinical pathologies [6]. It includes morphological, biochemical, 
and physiological changes in Müller cells and has mixed effects, contributing to neuroregeneration including protease activation, but also to neurodegeneration with impediment of tissue repair [3]. Müller cells are responsible for scar formation after retinal detachment with devastating consequences for recovery of visual function [6].

The up-regulation of GFAP within the Müller cells is a remarkably ubiquitous response in retinal pathology [7] and the most sensitive non-specific response to retinal disease and injury. Of note, GFAP is not required for normal functioning of Müller cells, only for Müller cell gliosis. Disintegration of Müller cells triggers cellular proteolysis. With proteolytic break-up of the GFAP polymer, soluble fragments of GFAP are released to the adjacent fluid compartments $[1,8]$. This process is calcium dependent and calpain-mediated release of a $41 \mathrm{kDa}$ fragment dominates over other, smaller proteolytic break-down products of GFAP [1].

Therefore, GFAP might be used as an indirect marker for retinal injury, Müller cell activation, protease activation and finally secondary degenerative processes in the retina $[2,7]$. Notably, there is experimental and clinical evidence for increased GFAP expression in retinal Müller cells in RD [9-14] and proliferative vitreoretinopathy $[15,16]$. Furthermore, the intraretinal glial response appears to be centrally involved in the formation of epiretinal gliosis (EG) [7]. Vitreous body proteomics has emerged as a tool to better understand and quantify the cellular processes underlying ocular disease [17, 18]. An advantage of enzyme-linked immunosorbent assay (ELISA) techniques is that the advanced analytical sensitivity allows detection of minute amounts of protein in a high throughput setting [1].

Therefore, we hypothesized that using a sensitive ELISA for GFAP [19] on vitreous body material from patients with $\mathrm{RD}$ and EG might permit us to detect GFAP from the human vitreous body, although GFAP has not yet been reported to be present in the vitreous body before. Interestingly, it was even absent in a large-scale proteomic study of patients suffering from a proliferative vitreoretinopathy (PVR), which revealed 97-137 vitreous body proteins [20]. This is surprising because GFAP is such an abundant protein, extremely stable and well suited for mass spectrometry [21]. Of note, the study by $\mathrm{Yu}$ et al. detected another intermediate filament, the neurofilament protein, albeit at a very low level. Using a highly sensitive ELISA, we previously described vitreous body neurofilament levels in a range of retinal pathologies [22]. We further hypothesised that, if detectable, vitreous body GFAP levels would be higher in these conditions compared with normal controls or patients with macular holes (MHs), where glial retinal pathology is less dominant.

\section{Materials and methods}

\section{Patients}

This study was approved by the ethics committees of the local clinical centres (Lublin, Poland and Erlangen, Germany) and adhered to the tenets of the Declaration of Helsinki. Acquisition of research samples was limited to routine sampling procedures. As a control, we included vitreous body material from cadaveric ocular tissue.

\section{Vitreous body homogenate}

Vitreous body samples were collected from 74 patients who underwent vitrectomy for RD $(n=46)$, EG $(n=15)$ and MH surgery $(n=13)$. Because it is ethically not possible to obtain vitreous body from healthy controls, we also included organ donors $(n=8)$. All samples were coded, snap-frozen and stored at $-80{ }^{\circ} \mathrm{C}$ until analysis. On receipt in London, the samples were thawed and homogenised on ice using a Sonipre 150 (power 14, one minute). The homogenate was spun down $\left(4{ }^{\circ} \mathrm{C}, 150,000 \mathrm{rpm}, 10 \mathrm{~min}\right.$ ) and the supernatant was used for analysis.

\section{Sample analysis}

All samples were analysed with the analyst being blinded to all other data.

A previously described, an ELISA technique was used to quantify vitreous body homogenate levels of GFAP [19]. In brief, microtitre plates were coated overnight with $100 \mu \mathrm{L}$ of the SMI26 capture antibody and diluted 1/5000 in 0.05$\mathrm{M}$ carbonate buffer, $\mathrm{pH}$ 9.5. The plate was washed with barbitone buffer containing 6-mM EDTA, 0.1-\% bovine serum albumin BSA and $0.05-\%$ Tween 20 ( $\mathrm{pH}$ 8.6). The plate was blocked with $250 \mu \mathrm{L}$ of barbitone buffer containing $6 \mathrm{mM}$ EDTA and $1 \%$ of BSA. After washing, $50 \mu \mathrm{L}$ of barbitone buffer, 6-mM EDTA, 0.1-\% BSA were added as sample diluent to each well. Fifty $\mu \mathrm{L}$ of standard or vitreous body homogenate samples were then added in duplicate to the plate. The plate was incubated at room temperature (RT) for $1 \mathrm{~h}$. After washing, $100 \mu \mathrm{L}$ of of horseradish peroxidase (HRP)-labelled rabbit anti-bovine GFAP diluted 1:1000 in barbitone buffer (6-mM EDTA, 0.1-\% BSA) were added to each well and the plate was incubated for $1 \mathrm{~h}$ at RT. After a final wash, $100 \mu$ l of tetramethylbenzidine (TMB) substrate were added. The plate was incubated for $20 \mathrm{~min}$ at RT in the dark; the reaction was stopped by adding $50 \mu \mathrm{l} 1$-M hydrochloric acid $(\mathrm{HCl})$ and the absorbance was read at $450 \mathrm{~nm}$ with $750 \mathrm{~nm}$ as the reference wavelength on a Wallac Victor 2 ELISA plate reader. 


\section{Data analysis}

All statistical analyses and graphs were done using SAS software (version 9.4, SAS Institute, Inc., Cary, North Carolina, USA). Both mean ( \pm standard deviation, SD) and median values were presented because non-Gaussian distribution independent variables were compared using the non-parametric two-sample exact Wilcoxon rank-sum test for two variables and a two-way unbalanced analysis of variance (ANOVA; general linear model (GLM)) for more than two variables. Fisher's exact test was used for comparing the proportion of patients with pathological (positive, high) GFAP levels because of small sample size and distribution. The cut-off above which results were considered pathological was defined as the highest value observed in the control group. The linear relationship between continuous variables was evaluated using the Spearman correlation coefficient. Multiple correlations were corrected using the Bonferroni method. Linear regression analysis was performed using the least squares method.

\section{Results}

The demographic features of the patients are summarised in Table 1. There was no difference in age between the groups $(F=1.40, p=0.3)$ and there was no correlation between the patients' age and the vitreous body GFAP levels for either the pooled cohort or any of the diagnostic groups.

The highest concentration of GFAP protein found in the vitreous body from the organ donor control group was $20 \mathrm{pg} / \mathrm{mL}$ (horizontal dotted line in Fig. 1). According to this cut-off, pathological vitreous GFAP levels were found in 8/15 (53\%) of the patients with EG, 1/13 (8\%) patients with MHs and 30/46 (65\%) patients with RD. The proportion of patients with pathological vitreous body GFAP levels were significantly higher following $\mathrm{RD}$ when compared to all organ donors (two-sided Fisher's exact test $p<0.0001$ ) and MHs $(p<0.0001)$. Likewise vitreous body GFAP levels were higher in a significantly larger proportion of patients with EG when compared to organ donors (two-sided Fisher's exact test $p=$ $0.0194)$ and MHs ( $p=0.0157)$. There was no significant difference in vitreous body GFAP levels between patients with RD and EG $(p>0.05)$.

Figure 1 shows the averaged GFAP levels (+SD) grouped according to the patients' diagnosis. The median value of the organ donors $(10 \mathrm{pg} / \mathrm{mL}$, range $10-20 \mathrm{pg} / \mathrm{mL})$ was comparable to the median value following MH surgery (median 10, range 0 to $30 \mathrm{pg} / \mathrm{mL}$ ). Medians were higher in EG (median 30, range 0 to $1100 \mathrm{pg} / \mathrm{mL}$ ) and $\mathrm{RD}(70$, range 0 to $1100 \mathrm{pg} / \mathrm{mL})$.

Vitreous body GFAP levels were not correlated to the time delay between onset of symptoms and sampling of the vitreous body ( $R=-0.09, p=0.6$, data not shown).
Patients with myopia ( $>-0.5 \mathrm{dpt}$ ) had significant higher median vitreous body GFAP levels $(50 \mathrm{ng} / \mathrm{mL})$ compared to those with hyperopia ( $20 \mathrm{pg} / \mathrm{mL}, p=0.024$, Fig. 2). Additionally, the axial length was correlated with vitreous body GFAP levels in the pooled cohort $(R=0.59, p=0.0005)$ as well as in patients with $\mathrm{EG}(R=0.69, p=0.027)$ or $\mathrm{RD}(R=0.52, p=$ 0.039).

\section{Discussion}

In the present study, we found increased levels of GFAP in the vitreous body of patients with RD and EG. The normal range of vitreous body GFAP levels was determined from donor eyes. The normal GFAP levels were below $20 \mathrm{pg} / \mathrm{mL}$. In $\mathrm{RD}$, the GFAP levels in the vitreous were increased 20 -fold, and in RG, the increase was 10-fold.

To the best of our knowledge, this is the first study quantifying GFAP levels in the human vitreous. GFAP has not yet been reported to be present in the vitreous body using a different technique [21]. Using a highly sensitive ELISA, we previously described vitreous body neurofilament levels in a range of retinal pathologies [22]. Thus, highly sensitive ELISA seems to be necessary to detect GFAP in the vitreous, too $[1,19]$.

The degenerative vitreous processes potentially induce pathology at the vitreoretinal interface [23, 24]. In RD, Müller cell hypertrophy and hyperplasia expand into the subretinal space and vitreous, and is associated with GFAP production [9, 25-27].

These unspecific responses of Müller cells start within 1 day of detachment $[12,28,29]$. At 3 days of detachment, the low basal level of GFAP mRNA in the normal retina is increased to approximately $500 \%$ [26] with GFAP labelling of Müller cells extending throughout the retina [30]. Elevated GFAP expression was found in Müller cells in early and longterm RD. Increased GFAP-containing intermediate filaments within Müller cells were found in 30- and 60-day detached retinas, as determined by protein gels, immunoblotting analysis, and light- and electron-microscopic immunocytochemistry $[9,31]$. Furthermore, tissue autoradiographic studies indicate an increase in RNA synthesis between 2 and 3 days after RD in Müller cells [32,33] in parallel with a five-fold increase in GFAP mRNA at that time using RNA blotting analysis and in situ hybridization [26].

In the vitreous, further translational studies are needed to address the time course, GFAP levels and outcome after surgical repair, as upregulation of intermediate filaments seems to be a crucial step for the gliotic response [3]. Epiretinal, intraretinal and subretinal reactive gliosis of Müller cells is a clinically significant limiting factor in the recovery of vision after reattachment $[14,34,35]$. It has been proposed that attempts to reduce Müller cell gliosis may inhibit subsequent 
Table 1 Patients characteristics (mean values \pm standard deviation)

\begin{tabular}{lllll}
\hline Characteristic & OD & EG & MH & RD \\
\hline Number & 8 & 15 & 13 & 46 \\
Age & $63 \pm 18$ & $70 \pm 7$ & $70 \pm 6$ & $64 \pm 15$ \\
Gender (F:M) & $4: 4$ & $8: 7$ & $8: 5$ & $14: 32$ \\
Onset to surgery (days) & - & $503 \pm 567$ & $116 \pm 55.4$ & $97.1 \pm 261$ \\
VA & - & $0.28 \pm 0.18$ & $0.18 \pm 0.09$ & $0.25 \pm 0.27$ \\
IOP & - & $12.3 \pm 2.9$ & $13.0 \pm 3.2$ & $11.7 \pm 4.4$ \\
Axial length [mm] & - & $23.7 \pm 1.9$ & $22.8 \pm 0.8$ & $24.5 \pm 2.3$ \\
PVR & - & - & - & $8 / 22(36 \%)$ \\
MD & - & - & - & $15 / 22(68 \%)$ \\
DM & $1 / 8(13 \%)$ & $1 / 7(14 \%)$ & $1 / 4(25 \%)$ & $5 / 21(24 \%)$ \\
RR & $1 / 8(13 \%)$ & $4 / 7(57 \%)$ & $3 / 5(60 \%)$ & $10 / 22(45 \%)$ \\
GFAP [pg/mL] & $11 \pm 4$ & $158 \pm 302$ & $12 \pm 9$ & $241 \pm 342$ \\
\hline
\end{tabular}

For those variables where the data was incomplete, the total number of patients (\%) is shown. $D M$ diabetes mellitus, $I O P$ intraocular pressure $(\mathrm{mmHg}), M D$ macular detachment, $M H$ macular hole, $P V R$ proliferative vitreoretinopathy, $R D$ retinal detachment, $R R$ arterial hypertension, $E G$ epiretinal gliosis, $M D$ macular degeneration, $O D$ organ donors, $V A$ visual acuity. $*=$ results are significantly different compared to patients with RD retinal degeneration and support neuroregeneration after reattachment $[14,35]$.

Interestingly, myopic eyes showed significant higher median GFAP levels in comparison to hyperopic eyes. Even though the numbers in this study are small, this finding is consistent with the literature on myopia as a relevant eye condition. Myopic eyes show more and severe retinal degeneration, more frequently RD [36] and, generally, the outcome from retinal repair surgery remains poorer [37].

The increased GFAP levels in EG in this study indicate the role of Müller cells in this retinal disease, too [38]. The normal levels of GFAP in MHs might be due to different unspecific or specific responses of Müller cells to the kind of stimulus in $\mathrm{MH}$ disease or to a small lesion size.

The limitations to this study are related to the fact that GFAP as a soluble protein biomarker can only provide indirect evidence for retinal pathology. Next, the definition of the cutoff value was based on organ donors, which cannot be regarded as a healthy control group. In addition, the postmortem interval was not recorded. It is, however, conceivable that artefactual vitreous GFAP levels in this study are unlikely because, technically, the removal of the eye is quicker than the spinal cord where absence of a post-mortem artefact for GFAP has been demonstrated [39]. In addition, the GFAP levels from
Fig. 1 A protein biomarker for glial (Müller cell and astrocytes) damage in retinal disease, vitreous body GFAP. According to the upper reference range (cutoff) of $20 \mathrm{pg} / \mathrm{mL}$ (horizontal reference line) high vitreous body homogenate GFAP levels were observed in $0 / 8(0 \%)$ of organ donors (OD), 1/13 (8 \%) of patients with a MH surgery, $8 / 15$ $(53 \%)$ of patients with EG and $30 / 46(65 \%)$ of patients with retinal detachment $(\mathrm{RD})$. The mean and standard deviation are shown

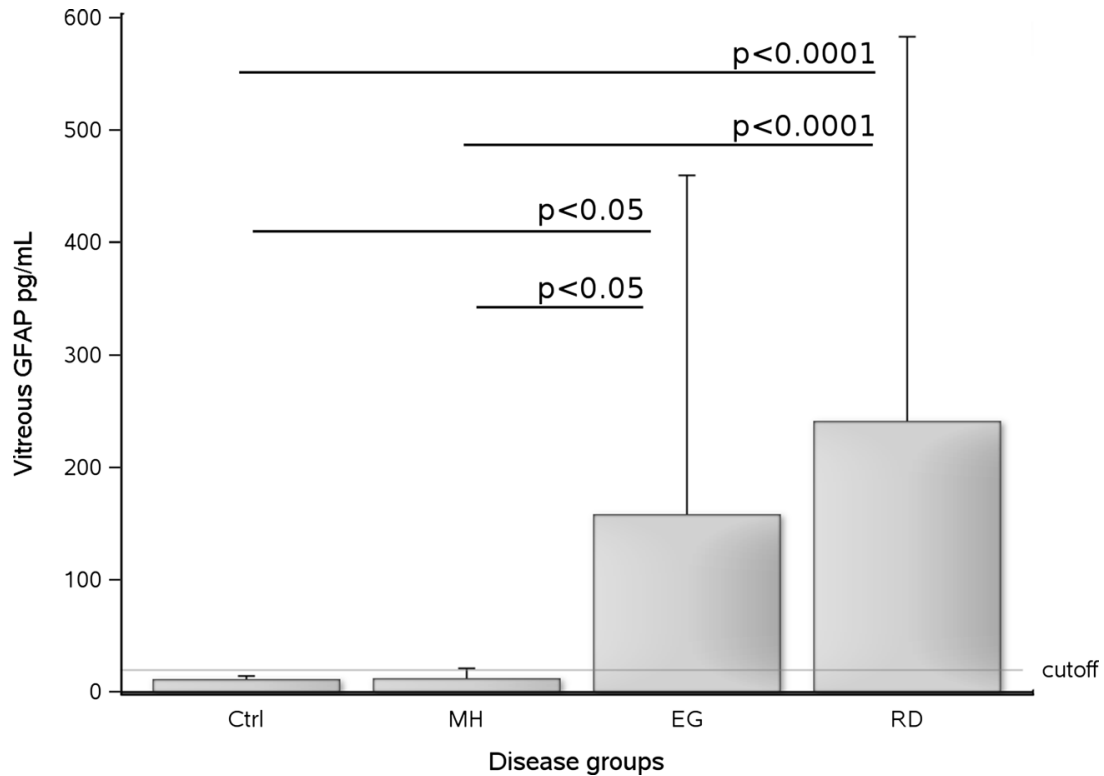


Fig. 2 Vitreous body GFAP levels were higher in patients with myopia $(n=22)$ compared to those without $(n=27, p=0.024)$.

The mean and SD are shown

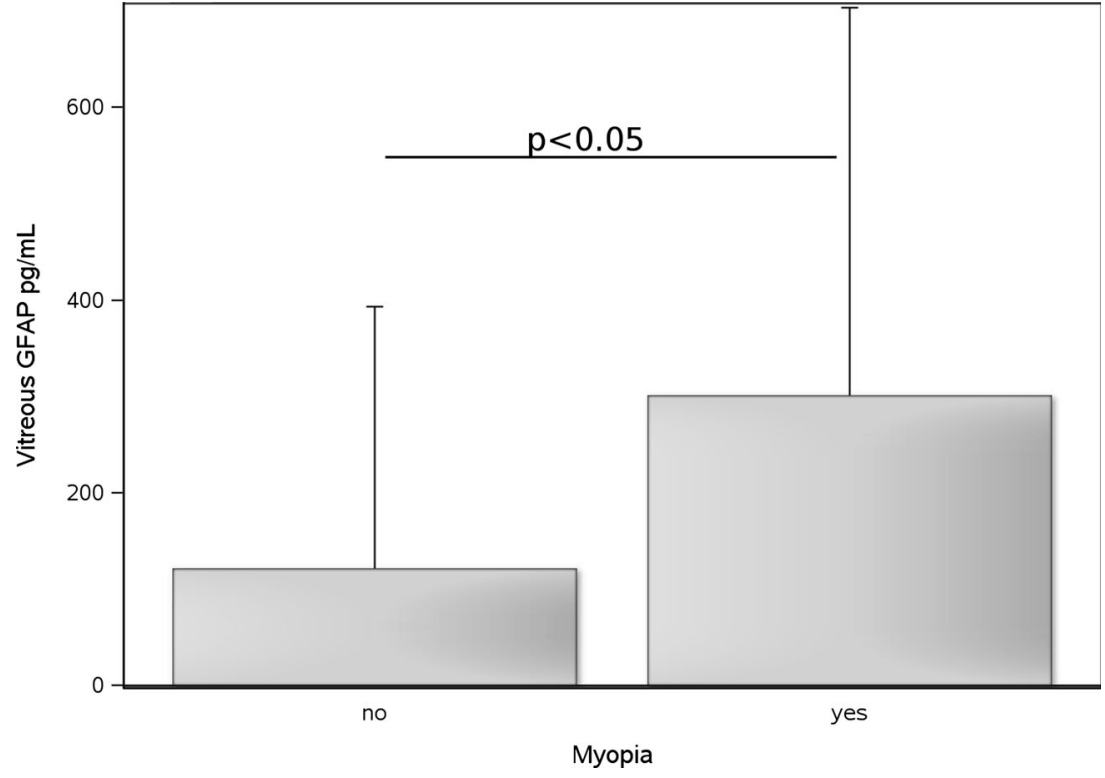

patients with a $\mathrm{MH}$ were in a comparable range to those from the organ donors. Taken together, this argues against a bias introduced by the post-mortem interval of the organ donors in the present study.

This study did not show a correlation between vitreous body GFAP levels and time delay onset of symptoms and sampling. This is likely due to the large time range (Table 1). This range exceeds what is known about the detachment-induced proliferation of Müller cells which peaks within 3 to 4 days $[13,28]$. The time lag of an average 91 days between RD to surgery might explain the lack of a time-GFAP correlation. But it might be also due to the relative weak power of historical data regarding the onset of symptoms and the range of RD duration. Other limitations of this study are the small numbers and the lack of follow-up. It would be of interest to discern if GFAP levels at time of surgery are of prognostic value in RD and EG. Extending on this limitation, the heterogeneous delay between symptom onset and sampling prevented us from performing a systematic investigation of RD severity with vitreous GFAP levels. Future studies on the prognostic value of vitreous body GFAP levels should include such severity data so as to enable testing the hypothesis that higher GFAP levels are present with more severe disease. Such studies will be a prerequisite for testing the clinical relevance of this biomarker. Finally, patient numbers were not equally balanced. There were relatively few patients with a $\mathrm{MH}$. Therefore, this study cannot exclude a limited degree of glial activation in MHs as suggested by the literature [40, 41].

In conclusion, we found, for the first time, increased GFAP levels in the vitreous of patients suffering from RD and EG. Because upregulation of GFAP is the most sensitive nonspecific response of Müller cells in retinal disease, vitreous
GFAP levels might act as a biomarker for retinal glial activation. GFAP levels in the vitreous were also elevated in cases of myopia. The data suggest that human vitreous body GFAP may be an interesting protein biomarker for indirect quantification of the glial response to retinal disorders. The small sample volume required for the ELISA can be further reduced using electrochemiluminescence- or fluorescence-based methods [1]. This opens avenues for future translational studies on the cell culture and animal models using vitreous body GFAP levels as a surrogate outcome.

Conflict of interest All authors certify that they have no affiliations with or involvement in any organization or entity with any financial interest (such as honoraria; educational grants; participation in speakers' bureaus; membership, employment, consultancies, stock ownership, or other equity interest; and expert testimony or patent-licensing arrangements), or non-financial interest (such as personal or professional relationships, affiliations, knowledge or beliefs) in the subject matter or materials discussed in this manuscript.

Open Access This article is distributed under the terms of the Creative Commons Attribution 4.0 International License (http:// creativecommons.org/licenses/by/4.0/), which permits unrestricted use, distribution, and reproduction in any medium, provided you give appropriate credit to the original author(s) and the source, provide a link to the Creative Commons license, and indicate if changes were made.

\section{References}

1. Petzold A (2015) Glial fibrillary acidic protein is a body fluid biomarker for glial pathology in human disease. Brain Res 1600:1731. doi:10.1016/j.brainres.2014.12.027

2. Bringmann A, Pannicke T, Grosche J et al (2006) Müller cells in the healthy and diseased retina. Prog Retin Eye Res 25:397-424. doi: 10.1016/j.preteyeres.2006.05.003 
3. Bringmann A, Iandiev I, Pannicke T et al (2009) Cellular signaling and factors involved in Müller cell gliosis: neuroprotective and detrimental effects. Prog Retin Eye Res 28:423-451. doi:10.1016/ j.preteyeres.2009.07.001

4. Eng LF, Gerstl B, Vanderhaeghen JJ (1970) A study of proteins in old multiple sclerosis plaques. Trans Am Soc Neurochem 1:42

5. Reeves SA, Helman LJ, Allison A, Israel MA (1989) Molecular cloning and primary structure of human glial fibrillary acidic protein. Proc Natl Acad Sci U S A 86:5178-5182

6. Lewis GP, Fisher SK (2006) Cellular effects of detachment of the neural retina and the retinal pigment epithelium. Retina, 4th edn. Mosby, St. Louis, pp 1991-2012

7. Lewis GP, Fisher SK (2003) Up-regulation of glial fibrillary acidic protein in response to retinal injury: its potential role in glial remodeling and a comparison to vimentin expression. Int Rev Cytol 230: 263-290

8. Eng LF, Ghirnikar RS (1994) GFAP and astrogliosis. Brain Pathol 4:229-237

9. Erickson PA, Fisher SK, Guérin CJ et al (1987) Glial fibrillary acidic protein increases in Müller cells after retinal detachment. Exp Eye Res 44:37-48

10. Okada M, Matsumura M, Ogino N, Honda Y (1990) Müller cells in detached human retina express glial fibrillary acidic protein and vimentin. Graefes Arch Clin Exp Ophthalmol 228:467-474

11. Guérin CJ, Anderson DH, Fisher SK (1990) Changes in intermediate filament immunolabeling occur in response to retinal detachment and reattachment in primates. Invest Ophthalmol Vis Sci 31: 1474-1482

12. Lewis GP, Matsumoto B, Fisher SK (1995) Changes in the organization and expression of cytoskeletal proteins during retinal degeneration induced by retinal detachment. Invest Ophthalmol Vis Sci $36: 2404-2416$

13. Geller SF, Lewis GP, Anderson DH, Fisher SK (1995) Use of the MIB-1 antibody for detecting proliferating cells in the retina. Invest Ophthalmol Vis Sci 36:737-744

14. Fisher SK, Lewis GP (2003) Müller cell and neuronal remodeling in retinal detachment and reattachment and their potential consequences for visual recovery: a review and reconsideration of recent data. Vis Res 43:887-897

15. Okada M, Matsumura M, Yamakawa R et al (1987) Immunoelectron microscopic study on glial fibrillary acidic protein (GFAP)-containing cells in preretinal proliferative tissue. Nippon Ganka Gakkai Zasshi 91:657-664

16. Nork TM, Wallow IH, Sramek SJ et al (1990) Immunocytochemical study of an eye with proliferative vitreoretinopathy and retinal tacks. Retina 10:78-85

17. Funatsu H, Yamashita T, Yamashita H (2006) Vitreous fluid biomarkers. Adv Clin Chem 42:111-166

18. Van Aken E, De Letter EA, Veckeneer M et al (2009) Transthyretin levels in the vitreous correlate with change in visual acuity after vitrectomy. Br J Ophthalmol 93:1539-1545. doi:10.1136/bjo.2009. 158048

19. Petzold A, Keir G, Green AJE et al (2004) An ELISA for glial fibrillary acidic protein. J Immunol Methods 287:169-177. doi: 10.1016/j.jim.2004.01.015

20. Yu J, Liu F, Cui S-J et al (2008) Vitreous proteomic analysis of proliferative vitreoretinopathy. Proteomics 8:3667-3678. doi:10. 1002/pmic.200700824

21. Ekegren T, Hanrieder J, Aquilonius S-M, Bergquist J (2006) Focused proteomics in post-mortem human spinal cord. J Proteome Res 5:2364-2371. doi:10.1021/pr060237f

22. Petzold A, Junemann A, Rejdak K et al (2009) A novel biomarker for retinal degeneration: vitreous body neurofilament proteins. J Neural Transm 116:1601-1606. doi:10.1007/s00702-009-0316-8
23. Byer NE (1994) Natural history of posterior vitreous detachment with early management as the premier line of defense against retinal detachment. Ophthalmology 101:1503-1513, discussion 15131514

24. Los LI, van der Worp RJ, van Luyn MJA, Hooymans JMM (2003) Age-related liquefaction of the human vitreous body: LM and TEM evaluation of the role of proteoglycans and collagen. Invest Ophthalmol Vis Sci 44:2828-2833

25. Charteris DG, Downie J, Aylward GW et al (2007) Intraretinal and periretinal pathology in anterior proliferative vitreoretinopathy. Graefes Arch Clin Exp Ophthalmol 245:93-100. doi:10.1007/ s00417-006-0323-5

26. Erickson PA, Feinstein SC, Lewis GP, Fisher SK (1992) Glial fibrillary acidic protein and its mRNA: ultrastructural detection and determination of changes after CNS injury. J Struct Biol 108:148-161

27. Erickson PA, Fisher SK, Anderson DH et al (1983) Retinal detachment in the cat: the outer nuclear and outer plexiform layers. Invest Ophthalmol Vis Sci 24:927-942

28. Fisher SK, Erickson PA, Lewis GP, Anderson DH (1991) Intraretinal proliferation induced by retinal detachment. Invest Ophthalmol Vis Sci 32:1739-1748

29. Lewis GP, Guérin CJ, Anderson DH et al (1994) Rapid changes in the expression of glial cell proteins caused by experimental retinal detachment. Am J Ophthalmol 118:368-376

30. Lewis GP, Sethi CS, Carter KM et al (2005) Microglial cell activation following retinal detachment: a comparison between species. Mol Vis 11:491-500

31. Lewis GP, Erickson PA, Guérin CJ et al (1989) Changes in the expression of specific Müller cell proteins during long-term retinal detachment. Exp Eye Res 49:93-111

32. Erickson PA, Fisher SK (1990) Tritiated uridine labeling of the retina: variations among retinal quadrants, and between right and left eyes. Exp Eye Res 51:145-152

33. Erickson PA, Guérin CJ, Fisher SK (1990) Tritiated uridine labeling of the retina: changes after retinal detachment. Exp Eye Res 51: $153-158$

34. Anderson DH, Guérin CJ, Erickson PA et al (1986) Morphological recovery in the reattached retina. Invest Ophthalmol Vis Sci 27: $168-183$

35. Francke M, Faude F, Pannicke T et al (2005) Glial cell-mediated spread of retinal degeneration during detachment: a hypothesis based upon studies in rabbits. Vis Res 45:2256-2267. doi:10. 1016/j.visres.2004.08.028

36. Mitry D, Charteris DG, Fleck BW et al (2010) The epidemiology of rhegmatogenous retinal detachment: geographical variation and clinical associations. Br J Ophthalmol 94:678-684. doi:10.1136/ bjo.2009.157727

37. Ross WH, Stock1 FA (2000) Visual recovery after retinal detachment. Curr Opin Ophthalmol 11:191-194

38. Guérin CJ, Wolfshagen RW, Eifrig DE, Anderson DH (1990) Immunocytochemical identification of Müller's glia as a component of human epiretinal membranes. Invest Ophthalmol Vis Sci 31:1483-1491

39. Petzold A, Groves M, Leis AA et al (2010) Neuronal and glial cerebrospinal fluid protein biomarkers are elevated after West Nile virus infection. Muscle Nerve 41:42-49. doi:10.1002/mus.21448

40. Bu S-C, Kuijer R, van der Worp RJ et al (2014) Glial cells and collagens in epiretinal membranes associated with idiopathic macular holes. Retina 34:897-906. doi:10.1097/IAE. 0000000000000013

41. Schumann RG, Eibl KH, Zhao F et al (2011) Immunocytochemical and ultrastructural evidence of glial cells and hyalocytes in internal limiting membrane specimens of idiopathic macular holes. Invest Ophthalmol Vis Sci 52:7822-7834. doi:10.1167/iovs.11-7514 